\title{
Transposition of Great Vessels
}

National Cancer Institute

\section{Source}

National Cancer Institute. Transposition of Great Vessels. NCI Thesaurus. Code C84742.

A congenital cardiac defect in which two heart vessels are reversed (transposed). 